\title{
FONTES, DOSES E MODO DE APLICAÇÃO DE NITROGÊNIO EM FEIJOEIRO NO SISTEMA PLANTIO DIRETO $\left({ }^{1}\right)$
}

\author{
FLÁVIO FERREIRA DA SILVA BINOTTI $\left({ }^{2}\right)$; ORIVALDO ARF $\left({ }^{3 *}\right)$; MARCO EUSTÁQUIO DE SÁ( $\left({ }^{3}\right)$; \\ SALATIER BUZETTI $\left({ }^{4}\right)$; ANGELA CRISTINA CAMARIM ALVAREZ $\left({ }^{5}\right)$; KARINA MARIE KAMIMURA $\left(^{6}\right)$
}

\section{RESUMO}

O manejo do $\mathrm{N}$ correspondente à maior produtividade de grãos, do ponto de vista econômico, muitas vezes não é o mais rentável e, portanto, não será adequado para recomendação ao produtor. O objetivo do trabalho foi o de estudar o efeito de fontes, doses e parcelamento do nitrogênio no desenvolvimento e na produtividade de grãos do feijoeiro de inverno no sistema plantio direto, correlacionado com análise econômica simples, em Latossolo Vermelho Distrófico argiloso, em Selvíria (MS), em 2005. O delineamento experimental foi o de blocos casualizados em esquema fatorial $3 \times 5 \times 2$, com trinta tratamentos e quatro repetições, constituídos por três fontes de nitrogênio (uréia, sulfato de amônio - SA e mistura - 1/2 N uréia + 1/2 N SA), cinco doses de $\mathrm{N}\left(0,50,100,150\right.$ e $\left.200 \mathrm{~kg} \mathrm{ha}^{-1}\right)$, aplicadas na semeadura ou parceladamente. Com o $\mathrm{N}$ proveniente do sulfato de amônio proporcionou-se mais produtividade de grãos e, com a uréia, maior eficiência econômica. A produtividade foi incrementada com o aumento da adubação nitrogenada até a dose de $198 \mathrm{~kg} \mathrm{ha}^{-1}$, proporcionando-se, em média, aumento de $44 \%$ na produtividade comparada à da testemunha sem N. O parcelamento da adubação nitrogenada não foi economicamente viável.

Palavras-chave: Phaseolus vulgaris L., manejo do nitrogênio, sulfato de amônio, uréia, modo de aplicação, viabilidade econômica.

\section{ABSTRACT \\ EFFECT OF SOURCES, DOSES AND NITROGEN SPLIT IN WINTER COMMON BEAN IN NO TILLAGE SYSTEM}

Several works show the efficiency of the nitrogen fertilization in the yield increase common bean yield; however, there is need of new studies, because of the economical point of view, the management of nitrogen that corresponds the largest yield of grains many times it does not correspond to the most profitable and, therefore, it does not fit for recommendation to the producer. The objective of the work was to study the effect of sources, doses and nitrogen split in the development and yield of winter common

( $\left.{ }^{1}\right)$ Parte integrante da Dissertação de Mestrado do primeiro autor. Recebido para publicação em 3 de outubro de 2006 e aceito em 6 de janeiro de 2009.

$\left({ }^{2}\right)$ Aluno de Pós-graduação em Sistema de Produção (Doutorado), Faculdade de Engenharia, UNESP - Campus de Ilha Solteira, 15385-000 Ilha Solteira (SP). E-mail flavio_agro@hotmail.com

${ }^{3}$ ) Departamento de Fitotecnia, Tecnologia de Alimentos e Sócio-Economia, Faculdade de Engenharia, UNESP - Campus de Ilha Solteira. E-mail: arf@agr.feis.unesp.br $\left(^{*}\right)$ Autor correspondente; mesa@agr.feis.unesp.br

$\left({ }^{4}\right)$ Departamento de Fitossanidade, Engenharia Rural e Solos, Faculdade de Engenharia, UNESP - Campus de Ilha Solteira. E-mail: sbuzetti@agr.feis.unesp.br

(5) Departamento de Produção Vegetal - Agricultura, Faculdade de Ciências Agronômicas, UNESP - Campus de Botucatu. E-mail:alvarez@fca.unesp.br

(6) Departamento de Solos, Universidade Federal do Rio Grande do Sul, UFRGS. E-mail: karinamarie.kamimura@gmail.com.br. 
bean in no tillage system, correlated with a simple economical analysis. The trial was conducted in Selvíria county, Mato Grosso do Sul, State, in 2005, in a dystrophic clayey Latosol - Haplustox. A randomized blocks design was used, in a factorial scheme $3 \times 5 \times 2$ with 30 treatments and 4 repetitions constituted by three sources of nitrogen (ammonium sulphate, urea and ammonium sulphate $1 / 2$ of $N+$ urea $1 / 2$ of $N$ ), with different doses of nitrogen $\left(0,50,100,150\right.$ e $\left.200 \mathrm{~kg} \mathrm{ha}^{-1}\right)$ applied at sowing or split $(1 / 3$ at sowing + $2 / 3 \mathrm{~V}_{4-4}$ growth stage). The source of nitrogen from ammonium sulphate provides larger yield of grains of the winter common bean; however, the urea is that provides larger economical efficiency. The increase of the nitrogen fertilization increases the yield up to $198 \mathrm{~kg} / \mathrm{ha}$ of $\mathrm{N}$, providing on average an increase of $44 \%$ in the yield compared with the control (without $\mathrm{N}$ ). The nitrogen split was not economically viable.

Key words: Phaseolus vulgaris L., nitrogen management, ammonium sulphate, urea, application way and economical viability.

\section{INTRODUÇÃO}

O feijoeiro é uma leguminosa de grande importância na economia brasileira, pois a população brasileira tem como parte de sua cultura, consumi-lo diariamente em suas refeições, visto que é um alimento com grande quantidade de proteínas. A partir da década de 70 , passou a ser cultivada também na época de inverno, sob irrigação, sendo atrativa aos médios e grandes produtores, geralmente usuários de maior nível de tecnologia. O manejo da adubação nitrogenada é de extrema importância, visto ser o nitrogênio o nutriente absorvido em maior quantidade pela cultura e de grande influência na produtividade.

No sistema plantio direto, com elevada disponibilidade de restos culturais com grande relação $\mathrm{C} / \mathrm{N}$, além das perdas de amônia por volatilização, o nitrogênio pode se tornar insuficiente para as plantas em função da imobilização microbiana, sendo necessárias doses mais elevadas desse nutriente. Relações em torno de 10/1 são favoráveis à mineralização enquanto quocientes mais largos, 50/1, por exemplo, em palhadas de cereais, o são à imobilização (MALAVOLTA, 2006). De acordo com Barbosa Filho et al. (2005), o efeito do N no feijoeiro pode ser negativamente influenciado pelos resíduos de cultura anterior, remanescentes na superfície. Em cultivo anterior à instalação dos experimentos de soja, desenvolveu-se, no solo, um ambiente de menos imobilização e de mais disponibilidade de $\mathrm{N}$ para as plantas de feijão, comparativamente à sucessão feijão após arroz, em que parte do $\mathrm{N}$ aplicado foi consumida pela população microbiana do solo no processo de decomposição da palhada do arroz, causando-se, assim, um déficit de $\mathrm{N}$.

De acordo com Barbosa Filho e Silva (2001), a uréia e o sulfato de amônio são duas fontes com pouca eficiência de utilização pelas culturas, raramente superior a $50 \%$; porém, são as mais utilizadas na agricultura brasileira, possivelmente devido ao menor custo e à disponibilidade no mercado. Enquanto outras fontes de $\mathrm{N}$ não estiverem disponíveis no mercado em condições competitivas com a uréia e o sulfato de amônio, a estratégia para a maximização da eficiência de uso de $\mathrm{N}$ ainda deverá ser feita pelo aperfeiçoamento de seu próprio manejo.

Em vários trabalhos, tem sido mostrado o efeito positivo da a aplicação de doses elevadas de nitrogênio no feijoeiro (BARbosa Filho e Silva, 2000; Stone e Moreira, 2001; BARBosa Filho et al., 2005; KIKUTI et al., 2005; Meira et al., 2005), sendo essas maiores que as atuais recomendadas; entretanto, há necessidade de estudos com relação à viabilidade econômica.

Devido aos fatores: pouca exigência inicial, possibilidade de perdas por lavagem e índice salino, na semeadura das culturas anuais aplica-se apenas uma fração da dose total do $\mathrm{N}$ necessário, sendo o restante aplicado em cobertura, sobre o solo, ao lado das plantas, nos períodos de mais exigência. Em alguns trabalhos com feijoeiro cultivado no inverno e com irrigação, entretanto, com a aplicação de todo o nitrogênio na semeadura, a produtividade tem sido semelhante àquelas nos tratamentos com parcelamento desse nutriente (CARVAlHo et al. 2001; VALÉrio et al., 2003; BinOTTI et al., 2007).

A pesquisa foi desenvolvida em Latossolo Vermelho, no município de Selvíria (MS), com o objetivo de se avaliar o efeito de fontes, doses e parcelamento do nitrogênio no desenvolvimento e na produtividade de grãos do feijoeiro de inverno, irrigado por aspersão, no sistema plantio direto, correlacionado a uma análise econômica simples.

\section{MATERIAL E MÉTODOS}

O cultivo de feijão foi efetuado na área experimental da Faculdade de Engenharia, UNESP Campus de Ilha Solteira, localizada no município de Selvíria (MS), no período de outono-inverno de 2005, com irrigação. O solo do local é Latossolo Vermelho Distrófico argiloso (EMBRAPA, 1999). Os teores de argila no solo eram de 456, 422 e $474 \mathrm{~g} \mathrm{~kg}^{-1}$, nas camadas 0 - 
0,10 m, 0,10-0,20 m e 0,20-0,40 m respectivamente. $\mathrm{Na}$ análise química do solo determinaram os seguintes valores: MO: $29 \mathrm{~g} \mathrm{dm}^{-3}, \mathrm{P}$ (resina): $20 \mathrm{mg} \mathrm{dm}^{-3}, \mathrm{pH}$ $\left(\mathrm{CaCl}_{2}\right): 4,8 ; \mathrm{K}, \mathrm{Ca}, \mathrm{Mg}$ e $\mathrm{H}+\mathrm{Al}: 2,5 ; 31 ; 13$ e 39 mmol $_{\mathrm{c}}$ $\mathrm{dm}^{-3}$ respectivamente, e $\mathrm{V}: 55 \%$. A precipitação pluvial média anual é $1.370 \mathrm{~mm}$, a temperatura média anual é $23,5^{\circ} \mathrm{C}$ e a umidade relativa do ar entre $70 \%$ e $80 \%$ (média anual). Durante o cultivo, a precipitação pluvial foi de $109 \mathrm{~mm}$, a temperatura média foi de 21,9 ${ }^{\circ} \mathrm{C}$ e a umidade relativa média do ar, $69 \%$.

O delineamento experimental foi em blocos casualizados, em esquema fatorial $3 \times 5 \times 2$, constituído por três fontes de nitrogênio (uréia, sulfato de amônio e mistura $-1 / 2$ de $\mathrm{N}$ da uréia $+1 / 2$ de $\mathrm{N}$ do sulfato de amônio), cinco doses de $\mathrm{N}(0,50,100,150$ e $200 \mathrm{~kg}$ $\left.\mathrm{ha}^{-1}\right)$, aplicadas em duas épocas: semeadura e parceladas (1/3 na semeadura $+2 / 3$ na fase $\left.V_{4-4}\right)$, com quatro repetições. As parcelas foram constituídas por cinco linhas de $6,0 \mathrm{~m}$ de comprimento espaçadas de $0,5 \mathrm{~m}$ entre si.

A semeadura foi realizada em área anteriormente cultivada com arroz de terras altas, em esquema anterior de sucessão de culturas (milho, feijão e arroz - cultura antecessora). Os tratamentos foram instalados em local onde o sistema plantio direto fora implantado no ano agrícola de 1996/1997. A área foi dessecada, utilizando-se o herbicida glyphosate (1560 $\mathrm{g} \mathrm{ha}^{-1}$ do i.a.). O feijão foi semeado, mecanicamente, em 19/5/2005, utilizando-se a cultivar Pérola, com 12-13 sementes viáveis por metro. A adubação básica, nos sulcos de semeadura, foi constituída por $60 \mathrm{~kg} \mathrm{ha}{ }^{-1}$ de $\mathrm{P}_{2} \mathrm{O}_{5}$ (superfosfato simples) e $30 \mathrm{~kg} \mathrm{ha}^{-1}$ de $\mathrm{K}_{2} \mathrm{O}(\mathrm{KCl})$. Nos tratamentos com aplicação do nitrogênio a mesma foi realizada perto da linha de semeadura tanto na adubação de semeadura e cobertura. A aplicação de nitrogênio em cobertura nos tratamentos que tiveram o parcelamento do $\mathrm{N}$ esta foi realizada no dia 17 de junho de 2005, ou seja, aos 23 dias após a emergência das plântulas na fase $\mathrm{V}_{4^{-}}(50 \%$ da plantas com a quarta folha trifoliolada expandida), de acordo com os estádios estabelecidos por FernAndez et al. (1986). Após a aplicação de nitrogênio, a área foi irrigada com o objetivo de se minimizar as perdas de nitrogênio por volatilização. O fornecimento de água, quando necessário, foi realizado por um sistema fixo de irrigação do tipo pivô central.

O controle e a prevenção das principais pragas e doenças na cultura foram realizados por meio de pulverizações com produtos recomendados para a cultura. Foram avaliadas as seguintes características: população de plantas (10 m de linha da área útil da parcela) inicial realizada na fase $\mathrm{V}_{2}$; população de plantas final (plantas ha ${ }^{-1}$ ); massa seca de 10 plantas na área útil da parcela (g planta $\left.{ }^{-1}\right)$ - coleta realizada no florescimento; teor de nitrogênio e enxofre na folha de 10 plantas na área útil da parcela $\left(\mathrm{g} \mathrm{kg}^{-1}\right)$ coleta realizada no florescimento; componentes de produção em avaliação realizada em 10 plantas em local predeterminado, para - número de vagens planta $^{-1}$, número de grãos planta ${ }^{-1}$, número de grãos vagem ${ }^{-1}$, massa de cem grãos e produtividade de grãos (avaliada em $10 \mathrm{~m}$ de linha, 13\% base úmida).

Realizou-se uma análise econômica simples, considerando-se os diferentes manejos da adubação nitrogenada (fonte, dose e modo de aplicação) correspondentes a cada tratamento do fatorial, atribuindo-se o custo de cada um deles, considerandose o preço da tonelada de cada adubo nitrogenado utilizado em agosto de 2005, na época de colheita do experimento (uréia $=\mathrm{R} \$ 2,81$; sulfato de amônio $=\mathrm{R} \$$ 4,14 e mistura $=\mathrm{R} \$ 3,50$ por $\mathrm{kg}$ de nitrogênio), e o custo da aplicação em cobertura, quando realizada (IEA, 2005). Com base na produtividade média de grãos em cada tratamento, calculou-se o acréscimo de produtividade proporcionado em relação à testemunha (sem N). Calculou-se o valor da produção correspondente àquele acréscimo de produtividade $\mathrm{e}$ a respectiva margem bruta de ganho com cada manejo da adubação nitrogenada utilizada, com base no preço médio de $\mathrm{R} \$ 65,00$ por saca de $60 \mathrm{~kg}$, pago ao feijão carioquinha, em Campo Grande (MS), em agosto de 2005 (AgrolinK, 2005).

Todos os efeitos dos tratamentos foram avaliados por meio da análise de variância, utilizando-se o programa SANEST (ZONTA e MACHADO, 1986).

\section{RESULTADOS E DISCUSSÃO}

A emergência das plântulas ocorreu aos sete dias após a semeadura. Aos 41 e 84 dias após a emergência das plântulas ocorreram o florescimento e a colheita do feijão respectivamente. As interações duplas e triplas entre os fatores pesquisados não foram significativas, e assim, apresentaram-se os efeitos simples dos fatores.

As populações inicial e final de plantas não foram influenciadas pelo modo de aplicação do nitrogênio, nem pelas diferentes fontes de nitrogênio (Tabela 1). Com o aumento das doses de nitrogênio houve diminuição nesses parâmetros, talvez em decorrência de mais salinização no sulco de semeadura, sendo comprometida a germinação das sementes, com consequente reflexo negativo na população de plantas. 
A massa seca de planta também não foi influenciada pelo modo de aplicação e pelas fontes de nitrogênio. Mas, com as doses de nitrogênio o efeito foi positivo, constatando-se ajuste a uma equação quadrática, na qual se evidenciou com a aplicação de nitrogênio, aumento da massa seca de planta até a dose de $154 \mathrm{~kg} \mathrm{ha}^{-1}$.

O maior teor de nitrogênio na folha foi proporcionado com a aplicação parcelada do nitrogênio, entretanto, essa variável não foi influenciada pelas deferentes fontes de $\mathrm{N}$ (Tabela 2). Com o aumento da dose de nitrogênio aplicada, também se verificou um aumento no teor de nitrogênio na folha. É importante salientar, entretanto, que os teores de nitrogênio avaliados em todos os tratamentos estão na faixa considerada adequada para a cultura, 30 a $50 \mathrm{~g} \mathrm{~kg}^{-1}$ (folha), de acordo com Ambrosano et al. (1997). Mesmo na testemunha, sem aplicação de nitrogênio, o teor nas folhas estava elevado, possivelmente devido à fixação simbiótica com báctérias nativas fixadoras de nitrogênio, somado ao nitrogênio proveniente da mineralização da matéria orgânica do solo. Por esse motivo, constatase a importância de mais estudos para identificar o momento entre a decomposição da fitomassa e a taxa de demanda da cultura sucessora, proporcionando- se, assim, mais eficiência na utilização do $\mathrm{N}$ proveniente da mineralização, obtendo-se, por conseqüência, mais retorno econômico e preservação ambiental, pela redução do uso de fertilizantes nitrogenados.

O teor de enxofre na folha foi influenciado pelo modo de aplicação de nitrogênio, sendo maior com a aplicação parcelada do N. Para as diferentes fontes de nitrogênio, não houve efeito para o sulfato de amônio, visto que o feijoeiro recebera esse nutriente em quantidades adequadas na adubação fosfatada na semeadura. O efeito do aumento das doses de nitrogênio no teor foliar de enxofre foi linear e positivo até a dose de $200 \mathrm{~kg} \mathrm{ha}^{-1}$ de $\mathrm{N}$ devido, provavelmente, à maior disponibilidade de nitrogênio no solo com a qual pode ter sido propiciado mais desenvolvimento radicular e exploração de maior volume de solo.

O número de vagens por planta não foi influenciado pelos modos e fontes de nitrogênio utilizadas. SoRATto et al. (2003) não verificaram diferença nessa variável com a aplicação de todo o $\mathrm{N}$ na semeadura ou com aplicação de $1 / 2$ na semeadura $+1 / 2$ em cobertura, utilizando a dose de $75 \mathrm{~kg} \mathrm{ha}^{-1} \mathrm{de}$ nitrogênio.

Tabela 1. População inicial, população final e massa seca de plantas em função dos modos de aplicação, fontes e doses de nitrogênio em feijoeiro irrigado no período de inverno. Selvíria (MS), 2005

\begin{tabular}{|c|c|c|c|}
\hline \multirow{2}{*}{ Tratamentos } & \multicolumn{2}{|c|}{ População de plantas } & \multirow{2}{*}{ Massa Seca } \\
\hline & Inicial Estádio $\mathrm{V}_{2}{ }^{*}$ & Final Colheita & \\
\hline & pla & 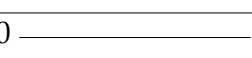 & g planta $^{-1}$ \\
\hline \multicolumn{4}{|l|}{ Modos de aplicação do nitrogênio } \\
\hline Aplicação total na semeadura & 211 & 187 & 10,91 \\
\hline $1 / 3$ semeadura $+2 / 3$ cobertura & 219 & 190 & 11,57 \\
\hline \multicolumn{4}{|l|}{ Fontes de nitrogênio } \\
\hline Uréia & 214 & 190 & 10,77 \\
\hline Sulfato de amônio (SA) & 215 & 191 & 11,38 \\
\hline Mistura $(1 / 2$ N uréia $+1 / 2$ N SA) & 215 & 185 & 11,56 \\
\hline \multicolumn{4}{|l|}{ Doses de nitrogênio $\left(\mathrm{kg} \mathrm{ha}^{-1}\right)$} \\
\hline 0 & $228^{(1)}$ & $206^{(2)}$ & $8,59^{(3)}$ \\
\hline 50 & 214 & 188 & 11,91 \\
\hline 100 & 210 & 185 & 11,36 \\
\hline 150 & 211 & 185 & 12,01 \\
\hline 200 & 211 & 179 & 12,31 \\
\hline $\mathrm{CV}(\%)$ & 9,9 & 10,3 & 25,3 \\
\hline
\end{tabular}

Médias seguidas de letras diferentes nas colunas, dentro de cada fator, diferem estatisticamente entre si pelo teste de Tukey a $5 \%$; ${ }^{*} 50 \%$ da plantas com folhas primárias expandidas. $\left({ }^{1}\right) \mathrm{Y}=222244,4444-4,00 \times$ e $\mathrm{R}^{2}=0,61 .\left({ }^{2}\right) \mathrm{Y}=199944,4444-113,0555 \times \mathrm{e} \mathrm{R}^{2}=0,75 .\left({ }^{3}\right) \mathrm{Y}=9,0354$ $+0,0428 x-0,00013 x^{2}$ e $R^{2}=0,80$. 
Tabela 2. Teores de nitrogênio e de enxofre nas folhas e, número de vagens por planta em função dos modos de aplicação, fontes e doses de nitrogênio em feijoeiro irrigado no período de inverno. Selvíria (MS), 2005

\begin{tabular}{|c|c|c|c|}
\hline \multirow{2}{*}{ Tratamentos } & \multicolumn{2}{|c|}{ Teor na folha } & \multirow{2}{*}{ Vagens planta $^{-1}$} \\
\hline & Nitrogênio & Enxofre & \\
\hline & 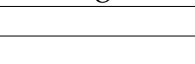 & & N. ${ }^{\circ}$ \\
\hline \multicolumn{4}{|l|}{ Modos de aplicação do nitrogênio } \\
\hline Aplicação total na semeadura & $44,85 \mathrm{~b}$ & $2,73 \mathrm{~b}$ & 13,06 \\
\hline $1 / 3$ semeadura $+2 / 3$ cobertura & 45,95 a & $2,88 \mathrm{a}$ & 12,98 \\
\hline \multicolumn{4}{|l|}{ Fontes de nitrogênio } \\
\hline Uréia & 45,24 & 2,79 & 12,31 \\
\hline Sulfato de amônio (SA) & 46,07 & 2,79 & 13,79 \\
\hline Mistura $(1 / 2$ N uréia + 1/2 N SA) & 44,89 & 2,83 & 12,95 \\
\hline \multicolumn{4}{|l|}{ Doses de nitrogênio $\left(\mathrm{kg} \mathrm{ha}^{-1}\right)$} \\
\hline 0 & $42,12^{(1)}$ & $2,61^{(2)}$ & $11,27^{(3)}$ \\
\hline 50 & 43,55 & 2,72 & 13,43 \\
\hline 100 & 44,33 & 2,79 & 13,14 \\
\hline 150 & 47,53 & 2,92 & 13,43 \\
\hline 200 & 49,47 & 2,97 & 13,81 \\
\hline $\mathrm{CV}(\%)$ & 4,9 & 7,7 & 22,1 \\
\hline
\end{tabular}

Médias seguidas de letras diferentes nas colunas, dentro de cada fator, diferem estatisticamente entre si pelo teste de Tukey a $5 \%$. $\left({ }^{1}\right) \mathrm{Y}=$ $42,1544+0,0177 x+0,000098 x^{2}$ e $R^{2}=0,99 .\left({ }^{2}\right) Y=2,6192+0,0018 x$ e $R^{2}=0,99 ;\left({ }^{3}\right) Y=11,5797+0,0271 x-0,000084 x^{2}$ e $R^{2}=0,80$

Os dados também são concordantes com os obtidos por RAPASSI et al. (2003) e ALVAREZ et al. (2005) utilizando uréia e nitrato de amônio. Com o aumento da adubação nitrogenada, entretanto, foi influenciada a produção de vagens por planta, constatando-se maiores valores com até $160 \mathrm{~kg} \mathrm{ha}^{-1}$ de nitrogênio. Teixeira et al. (2000), Silva et al. (2004), Alvarez et al. (2005) e TeIXEIRA et al. (2005) também obtiveram aumento no número de vagens planta ${ }^{-1}$ com a adubação nitrogenada.

Não se constatou efeito do modo de aplicação de nitrogênio no número de grãos por planta (Tabela 3). Com a utilização de sulfato de amônio, como fonte de $\mathrm{N}$, proporcionou-se maior número de grãos por planta se comparado à uréia, porém, sem diferença da fonte obtida pela mistura desses dois adubos nitrogenados. Para diferentes doses de nitrogênio, verificou-se que, com o aumento da dose de $\mathrm{N}$ foi proporcionado incremento no número de grãos por planta, até a dose de $148 \mathrm{~kg} \mathrm{ha}^{-1}$ de N. RAPASSI et al. (2003), Silva et al. (2004), Alvarez et al. (2005) e Teixeira et al. (2005) também verificaram essa mesma tendência.

O número de grãos vagem ${ }^{-1}$ não foi influenciado por quaisquer dos tratamentos utilizados, talvez por ser mais relacionado à cultivar utilizada e devido à reduzida influência das práticas culturais adotadas na cultura.
Ainda na tabela 3, não se verifica influência dos modos e fontes de nitrogênio na massa de cem grãos do feijão, dados concordantes com os obtidos por SoratTo et al. (2003).

Esses autores não verificaram influência nessa varável com a aplicação de todo o $\mathrm{N}$ na semeadura, ou com aplicação de $1 / 2$ na semeadura $+1 / 2$ em cobertura, utilizando a dose de $75 \mathrm{~kg} \mathrm{ha}^{-1}$ de nitrogênio. Com a aplicação de doses crescentes de nitrogênio até a dose de $187 \mathrm{~kg} \mathrm{ha}^{-1}$, propiciou-se aumento na massa de cem grãos. Os resultados têm respaldo nos obtidos por TEIXEIRA et al. (2000), RAPASSI et al. (2003), Silva et al. (2004), Alvarez et al. (2005) e TEIXEIRA et al. (2005), que constataram aumento na massa de cem grãos com a aplicação de nitrogênio.

Com o parcelamento da adubação nitrogenada não foi influenciada a produtividade de grãos do feijoeiro, pelo fato do experimento ter sido desenvolvido com fornecimento controlado de água em sistema de irrigação por aspersão, minimizandose as possíveis perdas do $\mathrm{N}$ por lixiviação. Soratto et al. (2003) não verificaram diferença na produtividade de grãos com a aplicação de todo o $\mathrm{N}$ na semeadura, ou com aplicação de $1 \frac{2}{2}$ na semeadura $+1 / 2$ em cobertura, utilizando a dose de $75 \mathrm{~kg} \mathrm{ha}^{-1} \mathrm{de}$ nitrogênio. 
Tabela 3. Número de grãos e vagens por planta, massa de cem grãos e produtividade de grãos em função dos modos de aplicação, fontes e doses de nitrogênio em feijoeiro irrigado no período de inverno. Selvíria (MS), 2005

\begin{tabular}{|c|c|c|c|c|}
\hline \multirow{2}{*}{ Tratamentos } & \multicolumn{2}{|c|}{ Número de grãos } & \multirow{2}{*}{$\begin{array}{c}\text { Massa } \\
\text { de } 100 \text { grãos }\end{array}$} & \multirow{2}{*}{$\begin{array}{c}\text { Produtividade } \\
\text { de grãos }\end{array}$} \\
\hline & Planta & Vagem & & \\
\hline & & & $\mathrm{g}$ & $\mathrm{kg} \mathrm{ha}^{-1}$ \\
\hline \multicolumn{5}{|l|}{ Modos de aplicação do nitrogênio } \\
\hline Aplicação total na semeadura & 68,58 & 5,26 & 23,83 & 2.504 \\
\hline $1 / 3$ semeadura $+2 / 3$ cobertura & 68,73 & 5,28 & 23,80 & 2.579 \\
\hline \multicolumn{5}{|l|}{ Fontes de nitrogênio } \\
\hline Uréia & $64,45 \mathrm{~b}$ & 5,22 & 23,77 & $2.489 \mathrm{~b}$ \\
\hline Sulfato de amônio (SA) & 73,21 a & 5,31 & 23,90 & $2.636 \mathrm{a}$ \\
\hline Mistura $(1 / 2$ N uréia + 1/2 N SA) & $68,31 \mathrm{ab}$ & 5,28 & 23,78 & $2.499 \mathrm{ab}$ \\
\hline \multicolumn{5}{|l|}{ Doses de nitrogênio $\left(\mathrm{kg} \mathrm{ha}^{-1}\right)$} \\
\hline 0 & $57,35^{1}$ & 5,11 & $22,53^{2}$ & $1.971^{3}$ \\
\hline 50 & 70,72 & 5,27 & 23,69 & 2.538 \\
\hline 100 & 70,34 & 5,36 & 24,02 & 2.563 \\
\hline 150 & 72,34 & 5,37 & 24,22 & 2.759 \\
\hline 200 & 72,54 & 5,24 & 24,63 & 2.877 \\
\hline CV (\%) & 23,1 & 8,7 & 3,3 & 10,5 \\
\hline
\end{tabular}

Médias seguidas de letras diferentes nas colunas, dentro de cada fator, diferem estatisticamente entre si pelo teste de Tukey a $5 \%$. $\left({ }^{1}\right) \mathrm{Y}=$ $58,8345+0,2009 x-0,00068 x^{2}$ e $R^{2}=0,88 .\left({ }^{2}\right) Y=22,638+0,0187 x-0,00005 x^{2}$ e $R^{2}=0,96 .\left({ }^{3}\right) Y=2031,4416+8,2122 x-0,0207 x^{2}$ e $R^{2}=0,93$

A produtividade de grãos do feijoeiro foi influenciada pela utilização de diferentes fontes de nitrogênio, obtendo-se menor produtividade quando se utilizou a uréia em relação ao sulfato de amônio porém sem diferença da fonte de $\mathrm{N}$ proveniente da mistura $(1 / 2 \mathrm{~N}$ uréia $+1 / 2 \mathrm{~N} \mathrm{SA})$. Talvez esse menor valor de produtividade, seja decorrente da volatilização da amônia, devido ao aumento da atividade microbiana favorável no sistema plantio direto com resíduo de arroz. Nessas condições, pode ter sido proporcionado mais estímulo à atividade da urease, com rápida decomposição da uréia e mais perda por volatilização; isso se refere á absorção tardia de nitrogênio, já que até a amostragem foliar os teores de $\mathrm{N}$ eram semelhantes entre as fontes de $\mathrm{N}$ utilizadas.

Na presença de resíduos vegetais podem ser aumentadas a concentração e a atividade da urease (NELSON et al., 1980; ECKERT et al., 1986; MCINNES et al., 1986 e Moal et al., 1995, citados por DA Ros et al., 2005). Também nos solos bem intemperizados constatam-se apresentam mais perdas de $\mathrm{N}-\mathrm{NH}_{3}$ (Costa et al., 2004). Barbosa Filho e Silva (2001), Rapassi et al. (2003), Barbosa Filho et al. (2004) e Alvarez et al. (2005), entretanto, não verificaram efeito de diferentes fontes de nitrogênio na produtividade do feijoeiro. BARBOSA Filho et al. (2005) determinaram diferenças na produtividade do feijoeiro com a aplicação de diferentes fontes, no cultivo de 2000, e resultados superiores com a uréia em comparação ao sulfato de amônio; entretanto, nos cultivos de 1999 e 2001, não se constataram tais efeitos.

Pode-se verificar aumento na produtividade de grãos até a aplicação de $198 \mathrm{~kg} \mathrm{ha}^{-1}$ de N, evidenciando-se o fato do feijoeiro ser responsivo às elevadas doses de nitrogênio em sistemas irrigados e quando cultivado sobre resíduo de gramíneas; há necessidade, entretanto, de se considerar a viabilidade econômica da aplicação de doses elevadas desse nutriente. Meira et al. (2005) também obtiveram incremento na produtividade do feijoeiro cultivado sobre arroz, até a dose de $164 \mathrm{~kg} \mathrm{ha}^{-1}$, e KIKUTI et al. (2005), em feijoeiro de inverno, com doses de $170 \mathrm{~kg}$ $\mathrm{ha}^{-1}$ e $144 \mathrm{~kg} \mathrm{ha}^{-1}$, respectivamente, em 2000 e 2002. Esse aumento na produtividade com o aumento da dose de $\mathrm{N}$ pode ser influência direta do aumento dos números de vagens e de grãos planta ${ }^{-1}$ e da massa de cem grãos, pois esses componentes de produtividade são considerados os de mais influência em feijoeiro. Esse efeito positivo em função de doses elevadas de nitrogênio pode ser decorrente da cobertura utilizada, a palhada de arroz (SiLveIRA et al., 2005).

É interessante ressaltar também a produtividade elevada no tratamento sem aplicação de nitrogênio (1.971 $\left.\mathrm{kg} \mathrm{ha}^{-1}\right)$. 
Na tabela 4 verifica-se maior margem bruta de ganho no tratamento em que se utilizou como fonte a mistura $(1 / 2$ de $\mathrm{N}$ da uréia $+1 / 2$ de $\mathrm{N}$ do sulfato de amônio), com aplicação de $150 \mathrm{~kg} \mathrm{ha}^{-1} \mathrm{de} \mathrm{N}$, em dose única, no sulco de semeadura ( $\mathrm{R} \$ 483,36$ por hectare). Entretanto, em determinadas condições, a população de plantas do feijoeiro pode ser comprometida por essa dose elevada de $\mathrm{N}$ na semeadura, conforme discutido anteriormente. Outro aspecto relevante é a dificuldade de aplicação de elevadas doses de $\mathrm{N}$, juntamente com os fertilizantes fosfatados e potássicos, no momento da semeadura. Com a utilização de 150 $\mathrm{kg} \mathrm{ha}^{-1}$ de $\mathrm{N}$, adotando-se como fonte o sulfato de amônio, aplicado em dose única no sulco de semeadura também foi proporcionada uma margem bruta de ganho elevado - $\mathrm{R} \$ 454,00$ por hectare. Com a aplicação de doses menores de nitrogênio (50 kg ha${ }^{1}$ ), usando a uréia ou o sulfato de amônio, independentemente do modo de aplicação, também se constatou viabilidade econômica.

Tabela 4. Custos com adubação nitrogenada, produtividade de grãos e acréscimo na produtividade devido à adubação nitrogenada, custo da aplicação, acréscimo financeiro e margem bruta de ganho devido à adubação nitrogenada

\begin{tabular}{|c|c|c|c|c|c|c|c|}
\hline \multicolumn{3}{|c|}{ Tratamentos } & \multirow[b]{2}{*}{$\begin{array}{l}\text { Produtividade } \\
\text { de grãos }\end{array}$} & \multicolumn{2}{|c|}{ Acréscimo } & \multirow{2}{*}{$\begin{array}{l}\text { Custo do } \\
\text { adubo }\left({ }^{2}\right)\end{array}$} & \multirow{2}{*}{$\begin{array}{c}\text { Margem bruta } \\
\text { de ganho }\end{array}$} \\
\hline Fontes & Doses & Modos de aplicação & & Produtividade & $\begin{array}{c}\text { Valor de } \\
\text { produção }\left({ }^{1}\right)\end{array}$ & & \\
\hline 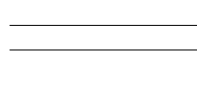 & 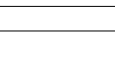 & $\mathrm{kg} \mathrm{ha}^{-1}$ & 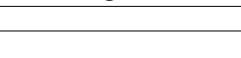 & $\bar{u}$ & 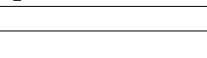 & $\mathrm{R} \$$ & 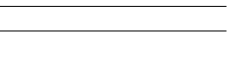 \\
\hline Uréia & 50 & \multirow{12}{*}{ 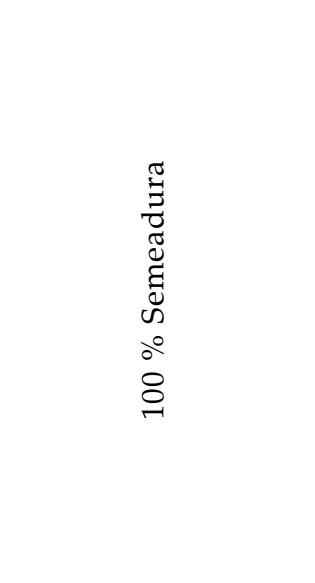 } & 2.479 & 508 & 548,78 & 140,50 & 408,28 \\
\hline Uréia & 100 & & 2.617 & 646 & 697,61 & 281,00 & 416,61 \\
\hline Uréia & 150 & & 2.691 & 720 & 777,80 & 421,50 & 356,30 \\
\hline Uréia & 200 & & 2.767 & 796 & 859,82 & 562,00 & 297,82 \\
\hline $\mathrm{SA}\left({ }^{3}\right)$ & 50 & & 2.550 & 579 & 625,32 & 207,00 & 418,32 \\
\hline SA & 100 & & 2.570 & 599 & 647,26 & 414,00 & 233,26 \\
\hline SA & 150 & & 2.966 & 995 & $1.074,80$ & 621,00 & 453,80 \\
\hline SA & 200 & & 3.129 & 1.158 & $1.250,51$ & 828,00 & 422,51 \\
\hline Mistura $\left({ }^{4}\right)$ & 50 & & 2.452 & 481 & 519,01 & 175,00 & 344,01 \\
\hline Mistura & 100 & & 2.642 & 671 & 725,02 & 350,00 & 375,02 \\
\hline Mistura & 150 & & 2.905 & 934 & $1.008,34$ & 525,00 & 483,36 \\
\hline Mistura & 200 & & 2.776 & 805 & 869,13 & 700,00 & 169,13 \\
\hline Uréia & 50 & \multirow{12}{*}{ 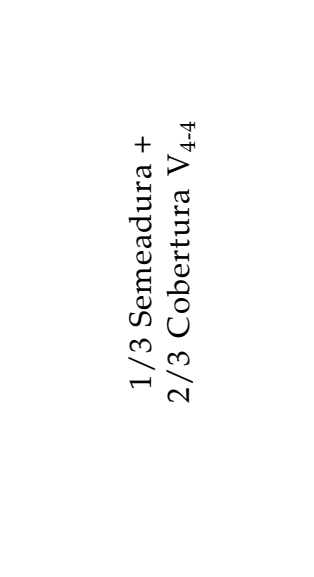 } & 2.521 & 550 & 594,27 & 160,50 & 433,77 \\
\hline Uréia & 100 & & 2.425 & 454 & 490,12 & 301,00 & 189,12 \\
\hline Uréia & 150 & & 2.606 & 635 & 685,73 & 441,50 & 244,23 \\
\hline Uréia & 200 & & 2.839 & 868 & 937,51 & 582,00 & 355,51 \\
\hline SA & 50 & & 2.600 & 629 & 679,46 & 227,00 & 452,46 \\
\hline SA & 100 & & 2.527 & 556 & 600,01 & 434,00 & 166,01 \\
\hline SA & 150 & & 2.746 & 775 & 836,87 & 641,00 & 195,87 \\
\hline SA & 200 & & 3.112 & 1.141 & $1.232,62$ & 848,00 & 384,62 \\
\hline Mistura & 50 & & 2.403 & 432 & 466,90 & 195,00 & 271,90 \\
\hline Mistura & 100 & & 2.593 & 622 & 672,23 & 370,00 & 302,23 \\
\hline Mistura & 150 & & 2.641 & 670 & 723,80 & 545,00 & 178,80 \\
\hline Mistura & 200 & & 2.640 & 669 & 722,52 & 720,00 & 2,52 \\
\hline
\end{tabular}

Testemunha 1.971

$(\operatorname{sem} \mathrm{N})$

$\left({ }^{1}\right)$ Com base no preço médio de R\$ 65,00 por saca de $60 \mathrm{~kg}$ do feijão carioquinha, pago em Campo Grande (MS), agosto de 2005 (AGROLINK, 2005).

$\left({ }^{2}\right)$ Preço do adubo (uréia $=\mathrm{R} \$ 2,81$; sulfato de amônio $=\mathrm{R} \$ 4,14$ e mistura $=\mathrm{R}$ \$ 3,50 por kg de nitrogênio, IEA, 2005), e da aplicação de cobertura quando necessária (IEA, 2005).

( $\left.{ }^{3}\right)$ Sulfato de amônio.

( $\left.{ }^{4}\right) 1 / 2$ N uréia + 1/2 N SA. 
É importante salientar, entretanto, que nos tratamentos em que se proporcionaram mais produtividades, com aplicação das maiores doses de $\mathrm{N}$ proveniente do sulfato de amônio, não se obteve maior margem bruta de ganho, por causa do maior custo do sulfato de amônio (SA) em comparação aos das outras fontes utilizadas. Do ponto de vista econômico, portanto, a dose de $\mathrm{N}$ correspondente à maior produtividade de grãos muitas vezes não é a mais rentável. Pode-se verificar que, de modo geral, a uréia foi a fonte de nitrogênio com a qual se obteve maior margem bruta de ganho em quase todos os tratamentos. Esses dados estão respaldados nos obtidos por Barbosa Filho e Silva (2001) que, ao realizaram análise econômica sobre fontes e doses de adubação nitrogenada, aplicados em pulverização no pivô ou por trator na cultura do feijão, concluíram ser a uréia aplicada superficialmente na água de irrigação a opção com mais retorno econômico, conforme também os obtidos por BARbosa Filho et al. (2004 e 2005).

O parcelamento da adubação nitrogenada não foi economicamente viável nesse estudo, pois as produtividades dos tratamentos com parcelamento do adubo nitrogenado foram semelhantes às de dose única de $\mathrm{N}$ no sulco de semeadura, visto que nos parcelamentos se gasta mais devido ao custo das aplicações. Também VALÉRIO et al. (2003) constataram ser possível a obtenção de produtividades próximas ao máximo, utilizando-se apenas $\mathrm{N}$ na semeadura, com redução da dose total de $\mathrm{N}$ aplicada. Essa opção, embora a mais econômica, não é facilmente adotada em algumas situações de campo.

\section{CONCLUSÕES}

1. A produtividade do feijoeiro irrigado no inverno não é influenciada pela aplicação parcelada ou não do nitrogênio.

2. A produtividade do feijoeiro irrigado no inverno é favorecida pelo $\mathrm{N}$ proveniente do sulfato de amônio e da mistura equitativa de uréia e de sulfato de amônio.

3. A produtividade do feijoeiro irrigado no inverno é favorecida pelo aumento da quantidade adubação nitrogenada até a dose de $198 \mathrm{~kg} \mathrm{ha}^{-1}$.

4. A maior margem bruta de ganho no feijoeiro irrigado no inverno é obtida com a mistura de uréia e de sulfato de amônio, em dose única de $150 \mathrm{~kg} \mathrm{ha}^{-1}$ de N.

5. O parcelamento da adubação nitrogenada não é economicamente viável.

\section{AGRADECIMENTO}

À Coordenação de Aperfeiçoamento de Pessoal de Nível Superior (CAPES), pela concessão da bolsa para a realização do projeto de pesquisa.

\section{REFERÊNCIAS}

AGROLINK. Cotação feijão. Disponível em:< http:// www.agrolink.com.br/cotacoes/pg_produto.asp?p1=6705>. Acesso em: 20 jan. 2005.

ALVAREZ, A.C.C.; ARF, O.; ALVAREZ, R.C.F.; PEREIRA, J.C.R. Resposta do feijoeiro à aplicação de doses e fontes de nitrogênio em cobertura no sistema de plantio direto. Acta Scientiarum, Maringá, v.27, n.1, p.69-75, 2005.

AMBROSANO, E.J.;TANAKA, R.T.; MASCARENHAS, H.A.A.; QUAGGIO, J.A.; CANTARELLA, H. Leguminosas e oleaginosas. In: Van RAIJ, B.; CANTARELlA, H.; QUAGGIO, J.A. Recomendações de adubação e calagem para o Estado de São Paulo. 2.ed. Campinas: IAC, 1997. p. 87-203. (Boletim Técnico,100)

BARBOSA FILHO, M.P.; FAGERIA, N.K., SILVA, O.F. Fontes e métodos de aplicação de nitrogênio em feijoeiro irrigado submetido a três níveis de acidez do solo. Ciência e Agrotecnologia, Lavras, v.28, n.4, p.785-792, 2004.

BARBOSA FILHO, M.P.; FAGERIA, N.K., SILVA, O.F. Fontes, doses e parcelamento da adubação nitrogenada em cobertura para feijoeiro comum irrigado. Ciência e Agrotecnologia, Lavras, v.29, n.1, p.69-76, 2005.

BARBOSA FILHO, M.P.; SILVA, O.F. Adubação e calagem para o feijoeiro irrigado em solo de cerrado. Pesquisa Agropecuária Brasileira, Brasília, v.35, n.7, p.1317-1324, 2000.

BARBOSA FILHO, M.P.; SILVA, O.F. Adubação de cobertura do feijoeiro irrigado com uréia fertilizante em plantio direto: um ótimo negócio. Informações Agronômicas, Piracicaba, n.93, p.1-5, 2001.

BINOTTI, F. F. S.; ARF, O.; ROMANINI JUNIOR, A.; FERNANDES, F. A.; SÁ, M. E.; BUZETTI, S. Manejo do solo e da adubação nitrogenada na cultura de feijão de inverno e irrigado. Bragantia, Campinas, v.66, n.1, p.121-129, 2007.

CARVALHO, M.A.C.; ARF, O.;SÁ, M.E.;BUZETTI, S.;SANTOS, N.C.B.; BASSAN, D.A.Z. Produtividade e qualidade de sementes de feijoeiro (Phaseolus vulgaris L.) sob influência de parcelamento e fontes de nitrogênio. Revista Brasileira de Ciência do Solo, Viçosa, v.25, n.3, p.617-624, 2001.

COSTA, A.C.S.; FERREIRA, J.C; SEIDEL, E.P.; CÁSSIO, A.T.; PINTRO, J.C. Perdas de nitrogênio por volatilização da amônia em três solos Argilosos tratados com uréia. Acta Scientiarum, Maringá, v.26, n.4, p.467-473, 2004.

DA ROS, C.O.; AITA, C.;GIACOMINI, S.J. Volatilização de amônia com aplicação de uréia na superfície do solo, no sistema plantio direto. Ciência Rural, Santa Maria, v.35, n.4, p.799-805, 2005. 
EMPRESA BRASILEIRA DE PESQUISA AGROPECUÁRIA Embrapa/CNPSo. Sistema Brasileiro de Classificação dos solos. Rio de janeiro: Embrapa/CNPSo, 1999. p.208.

FERNANDEZ, F.; GEPTS, P.; LOPES, M. Etapas de desarrollo de la planta de frijol (Phaseolus vulgaris L.). Cali: Centro Internacional de Agricultura Tropical, 1986. 34p.

INSTITUTO DE ECONOMIA AGRÍCOLA - IEA. Preços. Disponível em <http://www.iea.sp.gov.br/out/banco/ menu.phppreços>. Acesso em: 20 Jan., 2005.

KIKUTI, H.; ANDRADE, M.J.B.; CARVALHO, J.G.; MORAIS, A.R. Nitrogênio e fósforo em feijão (Phaseolus vulgaris L.) variedade cultivada BRS MG Talismã. Acta Scientiarum, Maringá, v.27, n.3, p. 415-422, 2005.

MALAVOLTA, E. Manual de nutrição mineral de plantas. São Paulo: Agronômica Ceres, 2006. p.130.

MEIRA, F.A.; SÁ, M.E.; BUZETTI, S.; ARF, O. Doses e épocas de aplicação de nitrogênio no feijoeiro irrigado cultivado em plantio direto. Pesquisa Agropecuária Brasileira, Brasília, v.40, n.4, p.383-388, 2005.

RAPASSI, R.M.A.; VALÉRIO FILHO, W.V.;SÁ, A.A.B.;SÁ, M.E.; CARVALHO, M.A.C.; BUZETTI, S.; ARF, O. Níveis e fontes de nitrogênio sobre o feijoeiro de inverno. Cultura Agronômica, Ilha Solteira, v.12, n.1, p.103-115, 2003.

SILVA, M.G.; ARF, O.;SÁ, M.E.; RODRIGUES, R.A.F.; BUZETTI, S. Manejo do solo e adubação nitrogenada em feijoeiro de inverno. Scientia Agrícola, Piracicaba, v.61, n.3, p.307-312, 2004.

SILVEIRA, P.M.; BRAZ, A.J.B.P.; KLIEMANN, H.J.; ZIMMERMANN, F.J.P. Adubação nitrogenada no feijoeiro cultivado sob plantio direto em sucessão de culturas. Pesquisa Agropecuária Brasileira, Brasília, v.40, n.4, p. 377-381, 2005.

SORATTO, R.P.; ARF, O.; RODRIGUES, R.A.F.; BUZETTI, S.; SILVA, T.R.B. Resposta do feijoeiro ao preparo do solo, manejo de água e parcelamento do nitrogênio. Acta Scientiarum, Maringá, v.25, n.1, p.89-96, 2003.

STONE, L.F.; MOREIRA, J.A.A. Resposta do feijoeiro ao nitrogênio em cobertura, sob diferentes lâminas de irrigação e preparos do solo. Pesquisa Agropecuária Brasileira, Brasília, v.36, n.3, p.473-481, 2001.

TEIXEIRA, C.M.; CARVALHO, G.J.; ANDRADE, M.J.B.; FURTINI NETO, A.E.; MARQUES, E.L.S. Palhadas e doses de nitrogênio no plantio direto do feijoeiro. Acta Scientiarum, Maringá, v.27, n.3, p.499-505, 2005.

TEIXEIRA, I.R.; ANDRADE, M.J.B.; CARVALHO, J.G.; MORAIS, A.R.; CORRÊA, J.B.D. Resposta do feijoeiro (Phaseolus vulgaris L. cv. Pérola) a diferentes densidades de semeadura e doses de nitrogênio. Ciência e Agrotecnologia, Lavras, v.24, n.2, p.399408, 2000.

VALÉRIO, C.R.; ANDRADE, M.J.B.; FERREIRA, D.F.; REZENDE, P.M. Resposta do feijoeiro comum a doses de nitrogênio no plantio e em cobertura. Ciência e Agrotecnologia, Lavras, v.27, Edição Especial, p.1560-1568, 2003.
ZONTA, E.P.; MACHADO, A.A. Sistema de Análise Estatística para microcomputadores - SANEST. Pelotas: UFPel, Instituto de Física e Matemática, 1986. 150p. 